\title{
Genetic variability and phylogenetic aspects in species of the genus Macrobrachium
}

\author{
A.L. Guerra ${ }^{1}$, A.V.B. Lima ${ }^{1}$, R.V. Lucato Júnior ${ }^{4}$, M.C. Chiachio ${ }^{2}$, \\ F.G. Taddei ${ }^{3}$ and L. Castiglioni ${ }^{3,4}$ \\ ${ }^{1}$ Departamento de Biologia, Universidade Estadual Paulista, \\ São José do Rio Preto, SP, Brasil \\ ${ }^{2}$ Departamento de Zoologia, Universidade Estadual Paulista, \\ São José do Rio Preto, SP, Brasil \\ ${ }^{3}$ Departmento de Biologia, Centro Universitário de Rio Preto, \\ São José do Rio Preto, SP, Brasil \\ ${ }^{4}$ Faculdade de Medicina de São José do Rio Preto, \\ São José do Rio Preto, SP, Brasil \\ Corresponding author: L. Castiglioni \\ E-mail: clilian@terra.com.br
}

Genet. Mol. Res. 13 (2): 3646-3655 (2014)

Received May 24, 2013

Accepted October 10, 2013

Published May 9, 2014

DOI http://dx.doi.org/10.4238/2014.May.9.7

\begin{abstract}
The genus Macrobrachium includes prawns, which are widely distributed in lakes, floodplains, and rivers in tropical and subtropical regions of South America. This genus presents nearly 210 known species with great ecological and economic importance. However, few studies are related to the biology of these crustaceans. In this study, we analyzed the genetic variability and phylogenetic relationship between Macrobrachium amazonicum and Macrobrachium jelskii, which are closely related species. Additionally, they are syntopics and their taxonomy poses problems because it is difficult to differentiate between the species. We used the mitochondrial gene sequences COI and 16S rRNA to assess the genetic structure of these species in 3 populations that were collected from Tiete hydrographic basin (São Paulo State, Brazil). The interspecific
\end{abstract}


comparison of samples that were collected at the same and different locations showed a low rate of genetic variability. This similarity was attributed to the recent introduction of these species in the regions that were sampled and the habitat conditions in which they inhabit. In addition, these results may be consistent with the hypothesis that they are a single species, interspecific hybrids, or metapopulation. The dendrogram analyses did not reveal the formation of clusters, confirming the disturbances in the genetic structure of the samples that were analyzed in this study. These data are pioneers to these crustaceans, and they confirm the ecological and evolutionary problems between these Macrobrachium species.

Key words: Macrobrachium; Crustacean; Genetic polymorphism; Genetic variability; COI; 16S rRNA

\section{INTRODUCTION}

The Macrobrachium Bate (1868) genus includes several species of prawns that are widely distributed in lakes, reservoirs, floodplains, and rivers in tropical and subtropical regions of South America, including all of the main river basins (Orinoco, Amazon, Araguaia, Tocantins, São Francisco, Paraná, and Paraguay River basins), as well as the smaller rivers of the South Atlantic Basin in the northern, northeastern, and eastern coasts of Brazil (Pereira et al., 2002; Melo, 2003; Short, 2004).

Most of the prawn species that have economic and ecological importance belong to the Macrobrachium genus. They are widely exploited by artisan fisheries and used as protein sources by humans and animals. In addition, these prawns show a high potential for aquaculture (Valenti, 1998; Magalhães, 2000; Magalhães et al., 2005; Moraes-Valenti and Valenti, 2007, 2010). However, their biological characteristics and genetic structure are still poorly understood.

Particularly, in the Upper Paraná and Tiete River, the occurrence of these species has been associated with ecological and conservation genetic studies; because they are exotic species, they were probably introduced as a result of human-mediated dispersion, either accidentally or for aquaculture (Magalhães et al., 2005; Guerra et al., 2010; Vergamine et al., 2011). However, besides their economic and ecological factors, Brazilian Macrobrachium species have been poorly studied, and genetic studies are important to reinforce these aspects.

In addition, it is important to consider the taxonomic problems between some $\mathrm{Mac}$ robrachium species. According to several authors, these processes are very difficult and questionable because the prawns seem to have high morphological conservation (Zhang et al., 2009; Guerra et al., 2010). This problem is more evident between Macrobrachium amazonicum and Macrobrachium jelskii, which are closely related and syntopic species. Furthermore, the high genetic similarity between them is consistent with the probable conditions of metapopulations or interspecific hybrids (Guerra et al., 2010).

In this study, we used the mitochondrial markers cytochrome oxidase subunit I (COI) and small subunit ribosomal RNA (16S rRNA) in the phylogenetic analysis and to assess the population genetic structure of M. amazonicum and M. jelskii. Mitochondrial 
genomes (mtDNA) have been considered a suitable molecular tool for systematics and molecular genetics in several species including freshwater prawns (Murphy and Austin, 2005; Chandra et al., 2006; Cook et al., 2008; Zhang et al., 2009; Vergamini et al., 2011). The mtDNA is a conserved protein-coding region with high variability in non-coding sequences that does not recombine. Sequence divergence accumulates more rapidly in mtDNA than in nuclear DNA because of a faster mutation rate and lack of repair system; meaning, it often contains high levels of informative variation (Khan et al., 2008). Although mtDNA evolved faster than the nuclear genome, the rate of evolution is different for different regions of mtDNA and has been used to examine various phylogenetic relationships. The COI gene is a mitochondrial gene region that is considered to be an important genetic marker for species identification (Dawnay et al., 2007). Likewise, the mitochondrial region 16S rRNA is a ribosomal RNA gene that is commonly used for phylogenetic studies at mid-categorical levels such as families or genera (Gerber et al., 2001). These aspects reinforce the use of these mtDNA sequences in this study.

\section{MATERIAL AND METHODS}

\section{Sample sources and DNA extraction}

DNA was extracted from fragments of abdominal muscles of M. amazonicum (Ma) and $M$. jelskii $(\mathrm{Mj})$ that were collected from the following sites in the Tiete hydrographic ba-

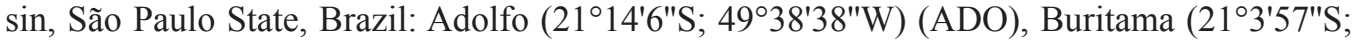

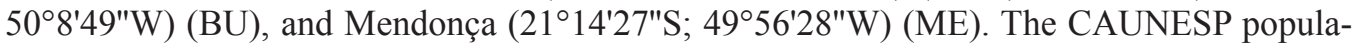
tion (CA) was obtained in FCAV/UNESP, Jaboticabal, São Paulo State, Brazil (21 ${ }^{\circ} 15^{\prime} 2^{\prime \prime}$ S; $48^{\circ} 18^{\prime} 5^{\prime \prime} \mathrm{W}$ ), which is an experimental population composed only of Ma. Potimirin glabra $(\mathrm{Pg})$, which was collected in Ubatuba, São Paulo State, Brazil (23⒉ $\left.26^{\prime} 13^{\prime \prime S} ; 4^{\circ} 04^{\prime} 08^{\prime \prime} \mathrm{W}\right)$ was used as an outgroup.

Genomic DNA was extracted using the QIAamp DNA Mini kit (Qiagen, Netherlands), according to manufacturer instructions. For the COI sequence analysis, we used 5 adults of each species from each location. For the 16S rRNA gene analysis, we used 3 adults of each species from each location.

Polymerase chain reaction (PCR) was conducted in an Eppendorf Thermal Cycler using the following universal primers: 16SF (5'-ACGCCTGTTTATCAAAAACAT-3') and 16Sa (5'-CCGGTCTGAACTCAGATCACGT-3') (Kocher et al., 1989) for the 16S rRNA, and COIa (5'-TAGACTTCTGGGTGGCCAAAGAATCA-3') and COI-f (5'-TCAACCAACCACAAA GACATTGGCAC-3') for the COI gene. The reactions mixtures contained the following reagents: $2.5 \mathrm{U}$ Gotaq $2 \mathrm{X}$ Master Mix, $3 \mathrm{mM} \mathrm{MgCl}, 10$ pmol forward and reverse primers, MilliQ autoclaved water, and $25 \mathrm{ng}$ genomic DNA. PCR products were separated on $1.0 \%$ agarose gels and purified using the GFX PCR DNA \& Gel Band kit (GE Healthcare and Life Technology) following manufacturer protocols and were sequenced in FCAV/UNESP/Jaboticabal, SP, Brazil.

The sequences of each individual were analyzed using the BioEdit 5.0.9 software (Hall, 1999). A consensus sequence was obtained for each DNA segment. Later, the sequences were aligned using the editor ClustalW (Thompson et al., 1997) linked to the DAMBE software (Xia and Xie, 2001). Then, the alignment was checked again by the BioEdit 5.0.9 software 
(Hall, 1999) and corrected manually where necessary. The nucleotide variation, substitution patterns, and genetic distance among the populations were assessed using the MEGA 4.0 software (Tamura et al., 2007). The calculation of intrapopulation and interpopulation divergence of the sequences was obtained using the model of nucleotide substitution Tamura3-parameter (Tamura, 2007) and a gamma (G) distribution to model the variations in the rate of substitution among the sites.

These tools were used to construct a dendrogram based on the neighbor-joining (NJ) method to obtain a graph of the Kimura 2-parameter genetic distribution pattern using the DAMBE 4.1.27 software (Xia and Xie, 2001). Bootstrap resampling (Felsenstein, 1985) was applied to evaluate the support for the single node (1000 repetitions).

\section{RESULTS}

The COI sequences varied in size from 590 to $715 \mathrm{bp}$, with a mean value of $680 \mathrm{bp}$. The composition of the nucleotide sequences was $0.293(\mathrm{~A}), 0.252(\mathrm{~T}), 0.259(\mathrm{C})$, and 0.196 $(\mathrm{G})$, and the total transition/transversion rate was $\mathrm{R}=6.58$. A corresponding saturation to the transition/transversion rate was not identified. The general mean genetic distance among all of the sequences from the different populations was $6.8 \%$. The intrapopulation genetic variability varied from 0.1 to $11 \%$ and with a mean of $4.01 \%$ (Table 1). The intrapopulation divergence value could not be obtained for the Mj population from Adolfo because the sequencing process was efficient for only 1 sample.

Table 1. Values of genetic divergence (\%) between the populations analyzed in this study.

\begin{tabular}{|c|c|c|c|c|c|c|c|c|}
\hline & $\mathrm{Ma} A D O$ & $\mathrm{Ma} \mathrm{BU}$ & $\mathrm{MaCA}$ & Ma ME & $\mathrm{Mj} \mathrm{ADO}$ & $\mathrm{Mj} \mathrm{BU}$ & $\mathrm{Mj} \mathrm{ME}$ & $\mathrm{Pg}$ \\
\hline Ma ADO & 0.1 & & & & & & & \\
\hline Ma BU & 0.6 & 0.9 & & & & & & \\
\hline $\mathrm{MaCA}$ & 3.1 & 3.5 & 5.2 & & & & & \\
\hline Ma ME & 1.1 & 1.4 & 4.1 & 1.5 & & & & \\
\hline $\mathrm{Mj} \mathrm{ADO}$ & 0.3 & 0.8 & 3.2 & 1.4 & - & & & \\
\hline $\mathrm{Mj}$ BU & 0.1 & 0.5 & 3.1 & 1.1 & 0.3 & 0.1 & & \\
\hline $\mathrm{Mj} \mathrm{ME}$ & 4.7 & 5.2 & 7.5 & 5.5 & 5.0 & 4.7 & 9.3 & \\
\hline $\mathrm{Pg}$ & 19.4 & 20 & 22 & 20 & 20 & 19.4 & 20 & 11 \\
\hline
\end{tabular}

The Mj population from Mendonça and Pg presented high divergence rates (9.3 and $11 \%$, respectively). The Ma population from Adolfo and Mj population from Buritama presented lower intrapopulation divergence rates $(0.1 \%$ in both populations). The Ma populations from Buritama $(0.9 \%)$ and Mendonça $(1.5 \%)$ also showed low divergence rates. In contrast, the population from CAUNESP had a high rate of divergence $(5.2 \%)$.

The interpopulation genetic divergence varied from 0.1 to $22 \%$ with a mean of $7.07 \%$ (Table 1). Table 1 shows that the interpopulation comparison of the same species involving the Ma groups from Buritama vs Adolfo presented the lowest divergence rate $(0.6 \%)$, followed by the group from Mendonça $v$ s Adolfo (1.1\%) and Mendonça vs Buritama (1.4\%). The other comparisons involving this species (Ma) showed high rates of interpopulation divergence: CAUNESP vs Buritama (3.5\%), CAUNESP vs Adulfo (3.1\%). 
In the interpopulation comparison involving $\mathrm{Mj}$, low genetic divergence rates were observed in the populations from Adolfo and Buritama (0.3\%). Higher divergence values were observed in the comparisons involving Mendonça vs Buritama (4.7\%) and Mendonça $v s$ Adolfo (5.0\%). All of the interpopulation comparisons involving the Pg outgroup showed extremely high genetic divergence values, varying from 19.4 to $22 \%$.

The interspecific comparison of the samples collected at the same location showed a low rate of genetic divergence in the $\mathrm{Ma}$ and $\mathrm{Mj}$ samples that were collected in Adolfo (0.3\%) and Buritama (0.5\%). Only samples that were collected in Mendonça presented high levels of interspecific divergence (5.5\%). The interspecific comparisons involving different localities also showed low rates of genetic divergence in the following groups: Ma from Adolfo vs $\mathrm{Mj}$ from Buritama (0.1\%) and Ma from Mendonça $v s \mathrm{Mj}$ from Adolfo (1.4\%). Higher levels of genetic divergence were found comparing Ma from Adolfo $v s$ Mj from Mendonça (4.7\%) and Ma from Buritama vs Mj from Mendonça (5.2\%). Samples that were obtained from CAUNESP were not analyzed interspecifically because it was composed only of Ma.

A dendrogram was obtained using the NJ method (presented with a consensus of $50 \%$-majority-rule), and the cluster frequencies are shown in each node (Figure 1). The cladogram that was obtained from the COI sequences that were analyzed did not show discriminative clusters. The Pg outgroup formed the most peripheral clade, with a bootstrap value of $99 \%$. The other individuals were grouped in a single node, composed of a clade that included $\mathrm{Mj}$ from Mendonça and another clade that included the other populations (bootstrap value of 99\%).

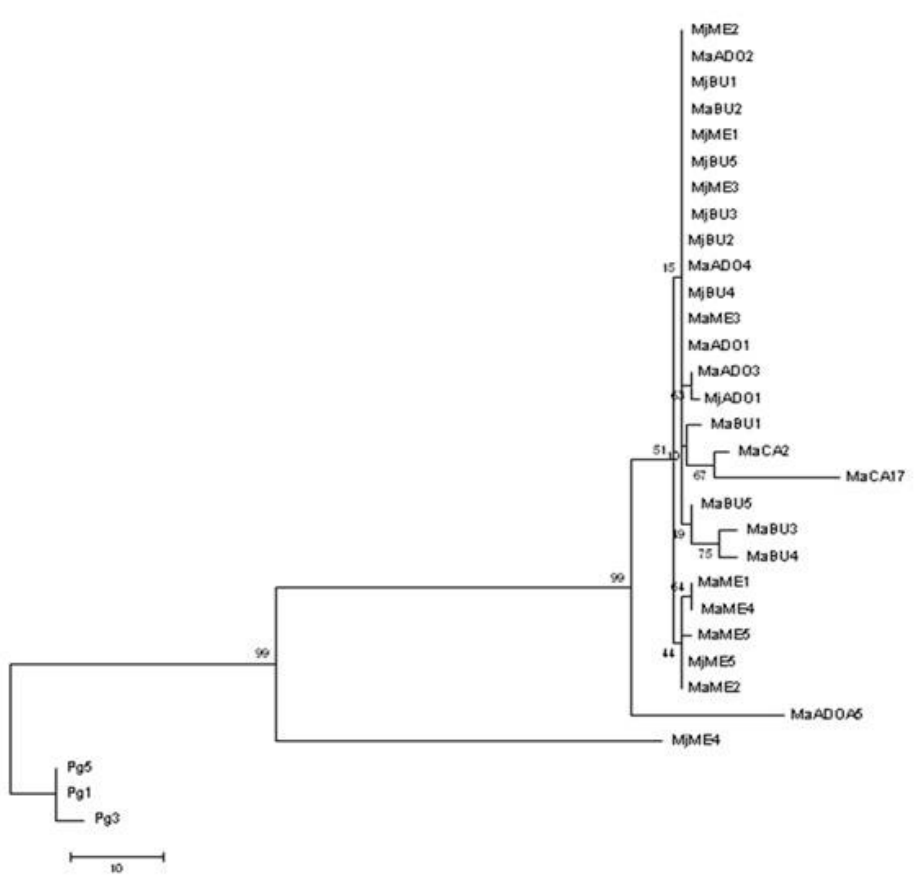

Figure 1. Dendrogram generated by the neighbor-joining method for the COI gene. The numbers at nodes represent the bootstrap values. 
The sequences obtained from the 16S rRNA varied in size from 520 to $529 \mathrm{bp}$, with a mean value of $520 \mathrm{bp}$. The nucleotide sequences were composed of 0.144 (A), 0.190 (T), 0.62 $(\mathrm{C})$, and $0.046(\mathrm{G})$. Corresponding saturations with transition/transversion rates were not found. The dendrogram from the 16S rRNA sequences (Figure 2) that was constructed using the NJ method (presented with a consensus of 50\%-majority-rule) did not show discriminative clusters. Only a population from CAUNESP formed a separated group (bootstrap value of 55\%).

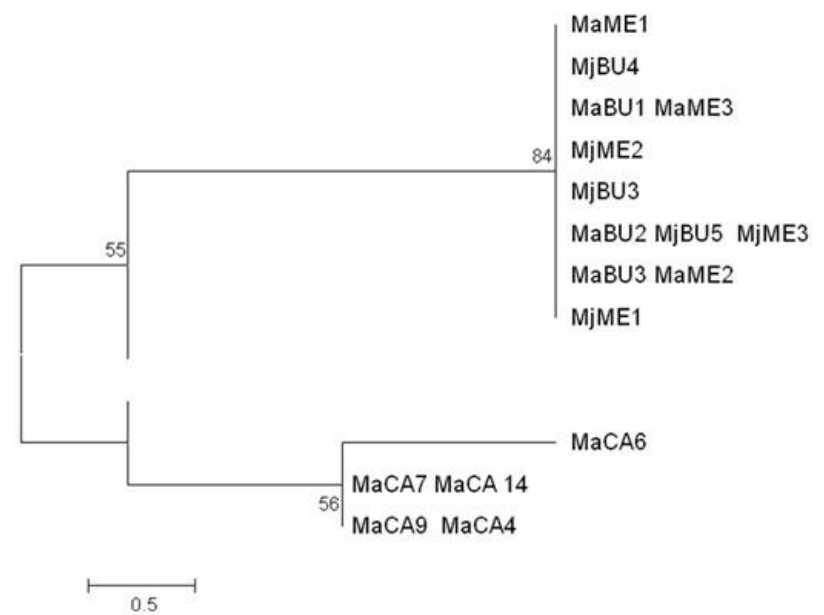

Figure 2. Dendrogram generated by the neighbor-joining method for the $16 \mathrm{~S}$ rRNA gene. The numbers at nodes represent the bootstrap values.

From the dendrogram of the combined analysis of both genes, the population from Adolfo were excluded because the sequencing process was efficient for only 1 sample. This dendrogram (Figure 3) also did not show discriminative clusters. Only a population of Mj that was collected in Mendonça formed a peripheral clade (bootstrap value of 99\%).

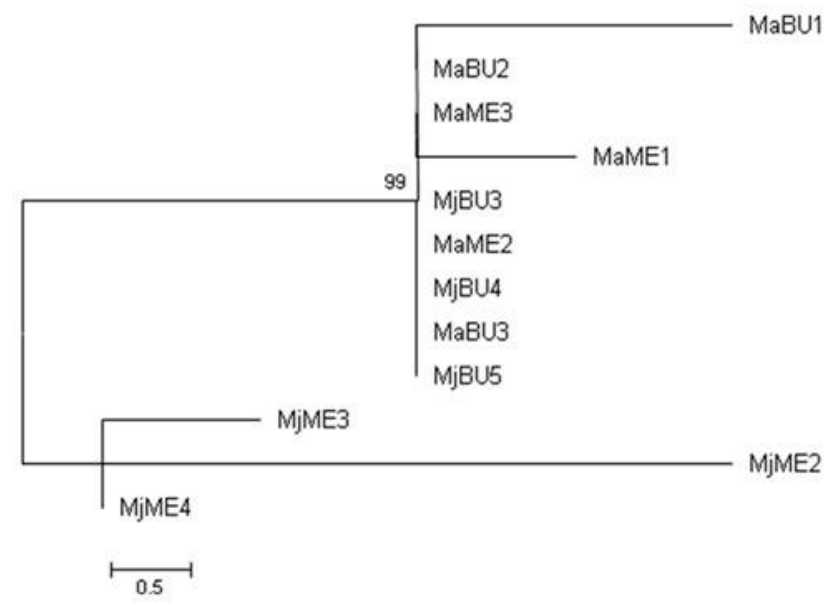

Figure 3. Dendrogram generated by the neighbor-joining method, using the IOC and 16S rRNA genes together. The numbers at nodes represent the bootstrap values. 


\section{DISCUSSION}

This study analyzed COI and 16S rRNA sequences in order to assess the genetic variability and the phylogenetic aspects in 2 species of prawns from the Macrobrachium genus (Mj and Ma), using Pg as an outgroup. The index of genetic divergence obtained in intrapopulation comparisons allowed us to describe the actual genetic structure of these populations. The index mean value for all of the intrapopulation comparisons was high (3.5\%). However, individually, these values are lower and very similar in most of the intrapopulation comparisons. This result reflects probable alterations in the genetic structure of these populations. The differences in the mean value of these indexes are related to the Mj populations from Mendonça and CAUNESP, which had higher indexes. The difference in the means that were observed in the CAUNESP population could be attributed to the long-term captivity, which makes the population genetically homogeneous. On the other hand, the high level of intrapopulation divergence in $\mathrm{Mj}$ from Mendonça can be attributed to human interference, which modified the population's genetic structure. The dam from Mendonça is constantly under human interference, mainly concerning the release of specimens that are used as live bait in the sport fishing (Magalhães et al., 2005; Guerra et al., 2010).

The interpopulation comparison showed wide variation in the genetic divergence rate. According to the analysis involving Ma samples, 3 combinations presented high levels of divergence (Ma from CAUNESP vs Adolfo: 3.1\%; Ma from CAUNESP vs Buritama: 3.5\%; and Ma from CAUNESP vs Mendonça: 4.1\%), all of which involve the captive population from CAUNESP. These results are interesting because there are doubts about the origin of the first $\mathrm{Ma}$ specimens that colonized the São Paulo State Rivers. The most accepted hypothesis is that these specimens are originally from Pará State, and the CAUNESP population was founded from animals in this state. Thus, the high divergence rates can refute the hypothesis that the species from São Paulo came from Pará. In the interpopulation comparisons involving Ma, the divergence rates were low and close (Ma from Adolfo $v s$ Mj from Buritama: 0.1\%; Ma from Mendonça $v s$ $\mathrm{Mj}$ from Buritama: 1.1\%; and Ma from Mendonça $v s$ Mj from Adolfo: 1.4\%), which confirms the common origin of these populations (Magalhães et al., 2005; Guerra et al., 2010).

A low genetic divergence value was observed comparing $\mathrm{Mj}$ from Adolfo vs Buritama $(0.3 \%)$. The other analysis presented high divergence values $(\mathrm{Mj}$ from Buritama vs Mendonça $=4.7 \%$ and $\mathrm{Mj}$ from Adolfo vs Mendonça $=5.0 \%$ ), but all of these comparisons involved the population that was collected in Mendonça dam, which showed a genetic imbalance in its population structure and was already discussed.

As mentioned previously, these species share some morphologic characteristics, and they are syntopic, which complicates their taxonomic identification (Pileggi, 2009; Guerra et al., 2010). Moreover, there are different morphotypes, which increases the doubts about the taxonomic identification of Ma and Mj (Vergamini et al., 2011).

To verify if the pattern of COI sequences reflected the presence of a single species, we performed interspecific comparisons that considered the same and different locations. The interspecific genetic divergence values of the samples that were collected at the same location were low in the population from Adolfo $(0.3 \%)$ and from Buritama $(0.5 \%)$, which consist of a single species, interspecific hybrids, or metapopulations. This result agrees with that from Guerra et al. (2010), who used the same species and the random amplification of polymorphic DNA-PCR method to show a high degree of phylogenetic similarity between Mj and Ma. Ac- 
cording to Guerra et al. (2010), the recent introduction of these species in the regions that were sampled and the habitat conditions may explain this low genetic differentiation. It is important to note that they are populations that inhabit dams and that the geographic isolation modifies the gene flow, increases inbreeding and the number of homozygous individuals, and reduces the genetic variability (Wright, 1960).

The sample from Mendonça presented high interspecific divergence rates $(5.5 \%)$. This result was already expected in an environment that is under human interference, which changes the variability and the genetic structure of these species. Three other interspecific comparisons involving different areas presented lower genetic divergences: Ma from Adolfo vs Mj from Buritama (0.1\%), Ma from Mendonça vs $\mathrm{Mj}$ from Buritama (1.1\%), and Ma from Mendonça $v s \mathrm{Mj}$ from Adolfo (1.4\%). The higher rates of genetic differentiation were found among the double comparisons only when the $\mathrm{Mj}$ samples from Mendonça were included in the analysis (Ma from Adolfo $v s \mathrm{Mj}$ from Mendonça: 4.7\%; Ma from Buritama $v s \mathrm{Mj}$ from Mendonça: 5.2\%), which reinforces the belief that the condition of the Mendonça population was probably related to different selective pressures.

Dendrogram analysis is an important tool for studies that involve population and species diagnosis. Several authors point out that the formation of different clusters in a dendrogram can be a good indicator that the populations are genetically structured and that a low rate or absence of gene flow can be distinguished in this population (Pereira, 1997; Murphy and Austin, 2002; Cheng et al., 2007). In this study, dendrograms were generated by the MEGA 4.0 software using only COI sequences and then grouping the COI and $16 \mathrm{~S}$ rRNA markers into the same analysis, and none of the analyses showed the formation of clusters. This result can indicate likely disturbances in the genetic structure of these samples that is probably due to anthropic action. This fact is more evident when we observe the position of $\mathrm{Mj}$ sample number 4 from Mendonça (MjME4), which formed a peripheral clade in both dendrograms, confirming the high values of intrapopulation genetic divergence that were obtained for this population ( $\mathrm{Mj}$ from Mendonça COI sequences demonstrated 9.3\% intrapopulation genetic divergence).

The dendrogram that was generated from 16S rRNA (MEGA 4.0 software) also did not show discriminative clusters. Only the population from CAUNESP formed a separate group (bootstrap value of 55\%), pointing out its differentiation relative to the other groups. The samples separating into 2 distinct groups refute the assumption of a common ancient origin among the local populations of Macrobrachium and the population from CAUNESP. As these data are pioneers in these organisms, other studies using different markers and new populations collected in other strategic geographic areas will elucidate these species migration routes and their likely genetic origin.

The hydrographic basins from São Paulo State have suffered great human interventions, which drastically modified the aquatic biota. Some of the interventions that we can list include impoundment, vegetation removal, inappropriate agricultural practices, and industrial pollution, which can modify the physical and chemical water parameters. The introduction of exotic species in a disturbed environment can selectively favor this exotic species instead of the native ones from mechanisms of predation and competition. Several studies have demonstrated the importance of maintaining endemic or native species on conservation and recovering natural areas as fundamental aspects of preserving the ecosystem biodiversity and for a better understanding of biotic and abiotic interactions (Magalhães et al., 2005; Lima et al., 2013).

The Macrobrachium genus presents a great diversity of representatives with a wide geographical distribution. Their highly variable morphology and the existence of morphotypes 
obstruct their taxonomic identification based only on these characteristics (Odinetz-Collart and Moreira, 1993; Odinetz-Collart and Magalhães, 1994; Porto, 1998; Bauzer et al., 2002; Anger et al., 2009). According to Zhang et al. (2009) and Murphy and Austin (2002), there are many doubts and inconsistencies about the phylogenetic and taxonomic aspects of a great number of species from this genus, and answers to many of these questions remain contradictory, even when using COI and 16S rRNA markers, which are thought to be efficient for this goal.

According to Anger et al. (2009), high rates of intraspecific genetic variability and consequently intra- and interpopulation genetic divergence can be a consequence of genetic isolation and likely mechanisms of incipient speciation. Because the species that were studied in this paper have wide geographic distributions and they occur in disturbed environments, the occurrence of morphological variation and the presence of varied morphotypes can suggest likely evolutionary changes inside these groups.

Data obtained in this study are pioneers to these crustaceans and confirm the ecological and evolutionary problems between these Macrobrachium species, principally concerning the $\mathrm{Mj}$ samples that were collected in Mendonça. Other studies involving these populations should provide substantial information for a better understanding of the questions related to the variability and differentiation of both crustacean species.

\section{ACKNOWLEDGMENTS}

Research supported by Fundação de Amparo à Pesquisa do Estado de São Paulo (FAPESP) and Centro Universitário de Rio Preto (UNIRP).

\section{REFERENCES}

Anger K, Hayd L, Knott J and Nettelmann U (2009). Patterns of larval growth and chemical composition in the Amazon river prawn, Macrobrachium amazonicum. Aquaculture 287: 341-348.

Bauzer LG, Gesto JS, Souza NA, Ward RD, et al. (2002). Molecular divergence in the period gene between two putative sympatric species of the Lutzomyia longipalpis complex. Mol. Biol. Evol. 19: 1624-1627.

Chandra SBC, Vlk JL and Kapatral V (2006). Comparative insect mitochondrial genomes: Differences despite conserved genome synteny. Afr. J. Biotechnol. 5: 1308-1318.

Cheng QQ, Fan QG, Xia LJ and Huang NY (2007). Sequence analysis of mitochondrial 16S rRNA gene of three species of Macrobrachium. Nat. Sci. 26: 1-6.

Cook BD, Pringle CM and Hughes JM (2008). Molecular evidence for sequential colonization and taxon cycling in freshwater decapod shrimps on a Caribbean island. Mol. Ecol. 17: 1066-1075.

Dawnay N, Ogden R, McEwing R, Carvalho GR, et al. (2007). Validation of the barcoding gene COI for use in forensic genetic species identification. Forensic Sci. Int. 173: 1-6.

Felsenstein J (1985). Phylogenies and the comparative method. Am. Nat. 125: 01-15.

Gerber AS, Loggins R, Kumar S and Dowling TE (2001). Does nonneutral evolution shape observed patterns of DNA variation in animal mitochondrial genomes? Annu. Rev. Genet. 35: 539-566.

Guerra AL, Lima AV, Taddei FG and Castiglioni L (2010). Genetic polymorphism, molecular characterization and relatedness of Macrobrachium species (Palaemonidae) based on RAPD-PCR. Genet. Mol. Res. 9: 2317-2327.

Hall TA (1999). BioEdit: a user-friendly biological sequence alignment editor and analysis program for Windows 95/98/ NT. Nucleic Acids Symposium Series 41: 95-98.

Khan HA, Arif IA, Al Homaidan AA and Al Farhan AH (2008). Application of 16S rRNA, cytochrome b and control region sequences for understanding the phylogenetic relationships in Oryx species. Genet. Mol. Res. 7: 1392-1397.

Lima AVB, Guerra AL, Almeida EA, Taddei FG, et al. (2013). Characterization of esterase patterns in hepatopancreas of three species of Macrobrachium (Palaemonidae). Biochem. Syst. Ecol. 47: 132-138.

Magalhães C (2000). Abbreviated development of M. jelskii (Crustacea: Decapoda: Palaemonidae) from the Rio Solimões foodplain, Brazil, reares in the laboratory. Nauplius 8: 1-14. 
Magalhães C, Bueno S, Bond G, Valenti WC, et al. (2005). Exotic species of freshwater decapod crustaceans in state of São Paulo, Brasil: records and causes of their introduction. Biol. Conserv. 14: 1929-1945.

Melo GAS (2003). Manual de Identificação dos Crustacea Decapoda de Água Doce do Brasil. Editora Loyola, São Paulo. Moraes-Valenti PMC and Valenti WC (2007). Effect of intensification on grow-out the Amazon River prawn Macrobrachium amazonicum. J. World Aquacult. Soc. 38: 516-526.

Moraes-Valenti P and Valenti WC (2010). Culture of the Amazon River Prawn Macrobrachium Amazonicum. In: Freshwater Prawns: Biology and Farming (New MB, Valenti WC, Tidwell JH and D'Abramo LR, eds.). WileyBlackwell, Oxford, 485-501.

Murphy NP and Austin CM (2002). A preliminary study of 16S rRNA sequence variation in Australian Macrobrachium shrimps (Palaemonidae: Decapoda) reveals inconsistencies in their current classification. Invertebrate Syst. 16: 697701.

Murphy NP and Austin CM (2005). Phylogenetic relationships of the globally distributed freshwater prawn genus Macrobrachium (Crustacea: Decapoda: Palaemonidae): biogeography, taxonomy and the convergent evolution of abbreviated larval development. Zoolog. Scripta 34: 187-197.

Odinetz-Collart O and Moreira LC (1993). Potencial pesqueiro de Macrobrachium amazonicum na Amazônia Central (Ilha do Careiro): variação da abundância e do comprimento. Amazoniana 12: 399-413.

Odinetz-Collart O and Magalhães C (1994). Ecological constraints and life history strategies of palaemonid prawns in Amazonia. Verhandlungen der Internationalen Vereinigung für Theoretische und Angewandte Limnologie, Stuttgart.

Pereira G (1997). A cladistic analysis of the freshwater shrimps of the family Palaemonidae (Crustacea, Decapoda, Caridea). Acta Biol. Venezuelica 17: 1-69.

Pereira G, Stefano H, Staton J and Farrell B (2002). Phylogenetic Relationships in Some Species of the Genus Macrobrachium Based on Nucleotide Sequences of the Mitochondrial gene Cytochrome Oxidase. Modern Approaches to the Study of Crustacea. Kluwer Academics, Plenum, New York.

Pileggi LG and Mantelatto FL (2009). Molecular phylogeny of the freshwater prawn genus Macrobrachium (Decapoda, Palaemonidae) with emphasis on the relationships among American species and the status of the type species. Invertebr. Systemat. 24: 194-208.

Porto AC (1998). Estrutura Populacional e Biologia Reprodutiva de Macrobrachium amazonicum (Heller, 1892) (Crustacea, Decapoda, Palemonidae), na Bacia Hidrográfica do Rio Meia Ponte. Bela Vista de Goiás, GO, Brasil. Master's thesis. Universidade de São Paulo, São Paulo.

Short JW (2004). A revision of Australian river prawns, Macrobrachium (Crustacea: Decapoda: Palaemonidae). Hydrobiologia 525: 1-100.

Tamura K, Dudley J, Nei M and Kumar S (2007). MEGA4: software Molecular Evolutionary Genetics Analysis (MEGA) versão 4.0. Biol. Mol. Evol. 24: 1596-1599.

Thompson JD, Gibson TJ, Plewniak, Jeanmougin F, et al. (1997). The CLUSTAL_X windows interface: flexible strategies for multiple sequence alignment aided by quality analysis tools. Nucleic Acids Res. 25: 4876-4882.

Valenti WC (1998). Carcinicultura de Água Doce. FAPESP/IBAMA, São Paulo.

Vergamini FG, Pileggi LG and Mantelatto FL (2011). Genetic variability of the Amazon River prawn Macrobrachium amazonicum (Decapoda, Caridea, Palaemonidae). Contributions Zool. 80: 67-83.

Wright S (1960). Physiological Genetics, Ecology of Populations, and Natural Selection. In: Evolution After Darwin (Tax S, ed.). University of Chicago Press, Chicago.

Xia X and Xie Z (2001). Dambe: Pacote de software para análise de dados em biologia molecular e evolução. J. Hered. 92: 371-373.

Zhang QY, Cheng QQ and Guan WB (2009). Mitochondrial COI gene sequence variation and taxonomic status of three Macrobrachium species. Zool. Res. 30: 613-619. 